\title{
Tagging film music: A corpus study of Max Steiner's film scores
}

\author{
Jeff Lyon ${ }^{1 \dagger}$ \\ Brent Yorgason ${ }^{2}$ \\ ${ }^{1}$ School of Music, Brigham Young University, Provo, UT, USA \\ ${ }^{2}$ Harold B. Lee Library, Brigham Young University, Provo, UT, USA \\ $\dagger$ Corresponding author: jeff lyon@byu.edu \\ Published 16 December 2021; https://doi.org/10.18061/FDMC.2021.0009 \\ Author video presentation and/or other conference material: https://doi.org/10.17605/OSF.IO/ZNVJQ
}

\begin{abstract}
The Max Steiner Digital Thematic Catalog is an ongoing corpus study project which will incorporate thematic data from all of Steiner's existing film scores (from 1930-1965). This film music corpus is significant because Steiner's work is representative of over three decades of Hollywood film scoring practices. Here we describe our methods and procedures in tagging film music data for an online database. Consistent metadata and tagging will help researchers to more effectively use the data in this corpus.
\end{abstract}

KEYWORDS: Max Steiner, film music, analysis, corpus studies, tagging

\section{Introduction}

The Max Steiner Digital Thematic Catalog is an ongoing corpus study project which will incorporate thematic data from all of Steiner's existing film scores. Max Steiner's film score collection at Brigham Young University comprises over 31,000 pages of film sketches spanning over 300 films from 1930 to 1965.[1] This corpus is significant because Steiner's work was quite influential and is representative of over three decades of Hollywood film scoring practices.

A central goal of the corpus study is to identify and analyze themes, theme variants, gestures, and other types of underscoring in each film. Our online database (accessible at https://maxsteinerinstitute.org) describes each musical cue in detail, providing a transcription of the score (either from existing sketches or by ear), a transcription of Steiner's handwritten annotations, precise timings, film stills, music-analytical data, and tags that relate each cue to the characters, events, places, and narrative structure of the film.

A detailed tagging system has been developed that will allow scholars to make comparisons between film cues and to find patterns across Steiner's sizable corpus. The average film has over 500 tags and the process of tagging them will likely take us over a decade. Thus, it is important to have a consistent tagging process with established procedures and categorization methods.
In order to consistently tag the cues in a film, we have established specific tagging categories. The core tagging categories are mood, action, character, setting, and scene (MACSS). Additional categories include object tags, music tags, film tags, and analytical tags. To further ensure tagging consistency, we have developed a set of automated tools to help us find conflicts and redundancies.

Most film tagging systems (such as the user-supplied tags found at IMDb) focus on the visual elements and plot points of a film. Our tagging system incorporates a specific focus on film music analysis, which introduces numerous terms not found in typical tagging schemas or established thesauri. We believe this will be very useful to scholars in the growing field of film music research.

\section{Method}

Here we describe further each of the tagging categories and the tools that we use to ensure consistency and to enable discovery.

\section{Tagging Categories}

The most significant step in the development of our tagging system was the creation of specific tagging categories. Every musical cue in the database is given a tag in each of the five core categories of MACSS (mood, action, character, setting, and scene).

\section{Table 1: The five core categories of MACSS}

\begin{tabular}{|l|l|l|}
\hline Category & Description & Examples \\
\hline Mood & $\begin{array}{l}\text { mood or emotion } \\
\text { of a musical cue }\end{array}$ & $\begin{array}{l}\text { tense, mysterious, dark, } \\
\text { comical, romantic }\end{array}$ \\
\hline Action & $\begin{array}{l}\text { action associated } \\
\text { with the cue }\end{array}$ & $\begin{array}{l}\text { walking, running, } \\
\text { dancing, falling, dying }\end{array}$ \\
\hline Character & $\begin{array}{l}\text { character types } \\
\text { involved in the cue }\end{array}$ & $\begin{array}{l}\text { hero, gangster, leading } \\
\text { lady, doctor, lawyer }\end{array}$ \\
\hline Setting & $\begin{array}{l}\text { location of the } \\
\text { musical cue }\end{array}$ & $\begin{array}{l}\text { prison, street, office, } \\
\text { barn, courtroom, boat }\end{array}$ \\
\hline Scene & $\begin{array}{l}\text { the scene type for } \\
\text { the current cue }\end{array}$ & $\begin{array}{l}\text { establish character, } \\
\text { conflict, flashback, } \\
\text { climax, love scene }\end{array}$ \\
\hline
\end{tabular}


There are also several optional tagging categories to be used whenever possible and applicable: film (or movie) tags, music tags, analytical tags, physical object tags, and concept tags.[2]

\section{Table 2: Additional optional tagging categories}

\begin{tabular}{|l|l|l|}
\hline Category & Description & Examples \\
\hline $\begin{array}{l}\text { Film (or } \\
\text { Movie) }\end{array}$ & $\begin{array}{l}\text { film techniques } \\
\text { used in the cue }\end{array}$ & $\begin{array}{l}\text { montage, voice-over, } \\
\text { double exposure }\end{array}$ \\
\hline Music & $\begin{array}{l}\text { significant aspects } \\
\text { relating to music }\end{array}$ & $\begin{array}{l}\text { source music, quotation, } \\
\text { stinger, mickey-mousing }\end{array}$ \\
\hline Analytical & $\begin{array}{l}\text { music-analytical } \\
\text { terminology }\end{array}$ & $\begin{array}{l}\text { ostinato, sequence, tone- } \\
\text { cluster, AABA structure, } \\
\text { octatonic, parallelism }\end{array}$ \\
\hline $\begin{array}{l}\text { Thing } \\
\text { (physical) }\end{array}$ & $\begin{array}{l}\text { important physical } \\
\text { objects in the cue } \\
\text { phonograph, newspaper }\end{array}$ & $\begin{array}{l}\text { death, murder, fear, } \\
\text { deception, love, war }\end{array}$ \\
\hline $\begin{array}{l}\text { Thing } \\
\text { (conceptual) }\end{array}$ & $\begin{array}{l}\text { central concepts } \\
\text { involved in the cue }\end{array}$ & $\begin{array}{l}\text { deater, } \\
\text { dection, }\end{array}$ \\
\hline
\end{tabular}

Overall, our philosophy is to tag each film cue with as much data as possible, with the categories providing a crucial guide for potential tags.

\section{Tools for Consistency}

Since the tagging process will take place over a period of several years, we needed to develop tools to ensure consistency over time. The Tag Data tool in the database lists and enumerates all tags across all categories (see Figure 1). It provides a quick reference for the most commonly-used tags in the database and a reminder of the proper formatting and spelling of tags.[3]

\begin{tabular}{|l|l|l|l|l|l|}
\hline \multicolumn{2}{|l|}{ Mood/Imotion } & \multicolumn{2}{l|}{ Action } & Character \\
\hline tense & 455 & conversing & 278 & leading man & 514 \\
dramatic & 263 & walking & 157 & leading lady & 473 \\
mysterious & 219 & running & 97 & hero & 422 \\
dark & 167 & singing & 65 & heroine & 419 \\
somber & 145 & arguing & 63 & gangster & 265 \\
cheerful & 101 & driving & 55 & antagonist & 221 \\
calm & 82 & dancing & 47 & lawyer & 107 \\
gentle & 77 & falling & 46 & teenager & 107 \\
romantic & 59 & escaping & 45 & FBI & 81 \\
\end{tabular}

\section{Figure 1: Tag Data tool}

Before adding a new tag to the database, we often check the Tag Data to determine if there is an existing tag that could be a better fit. We are also developing an integrated thesaurus that creates a link between related terms in the database (such as turbulent, agitated, and distressed) even if we decide to use them separately.
After we have finished tagging a film, we use the Unique Tags tool to identify tags that were used only in that film. If we have formatted a tag differently than usual (such as "onscreen" vs. "on-screen"), it will appear as a unique tag and we will standardize it. For instance, the unique tags shown in Figure 2 for the 1939 film Dust Be My Destiny include the tag "end credits," which we would standardize as "end title sequence."'[4]

\section{dark room bank sincere barn inversion theater expectant milkman jailer buzzy thankful road end credits kind COW resting pensive photography hitch= hiking bribe settling down Rimsky-Korsakov oppressive denial devotion hiccuping hook injustice mooing car horn millk intervallic expansion}

\section{Figure 2: Unique Tags tool}

More recently we have started to use OpenRefine, an open source tool for data cleanup (https://openrefine.org). This tool has helped us to more efficiently identify inconsistently formatted tags as well as tags that have been assigned to multiple categories (as described further in the Discussion section below).

\section{Tools for Discovery}

We have also developed tools to enable discovery. All of the tags displayed in the online database are hyperlinked to the Tag Search feature, which allows users to search for tags across all films (see the "murder" search in Figure 3). The Thesaurus provides users with alternative search terms ("execution," "murdering," and "death"). And Tag Clouds (similar to the one shown in Figure 2) allow users to easily see the most-used tags within a film.

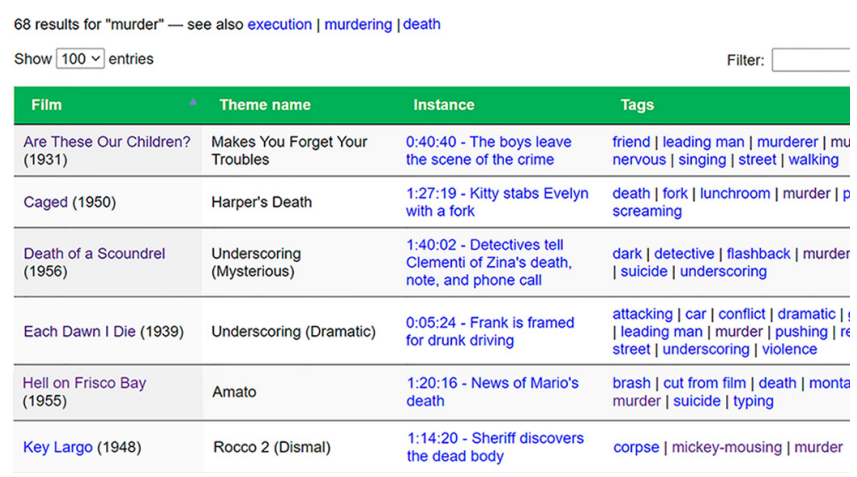

Figure 3: Tag Search tool 


\section{Results}

Although the tagging process for the Steiner corpus is still underway, the data collected so far has already provided ample material for film music research (Lyon 2021; Yorgason 2020, 2021). Here, we provide the results of a hypothetical research question using information currently in the online database. Steiner is known for his use of the technique of "mickey-mousing," which means that he frequently "catches the action" on the screen with musical gestures in his score. A film music scholar might pose the following questions: (1) How frequently does Steiner use mickey-mousing? (2) Does mickeymousing increase or decrease over time? (3) Which actions are most frequently mickey-moused? (4) Which film genres use mickey-mousing the most?

\section{Frequency}

Using the Tag Data tool, we find that the tag "mickeymousing" is used 272 times out of 1,674 total cues. Thus, Steiner uses the technique of mickey-mousing in $16.2 \%$ of all musical cues in the current database.

\section{Increase or Decrease over Time}

Consulting the data for individual films in the database, we find "mickey-mousing" tagged more than twice as many times in Steiner's later Warner Bros. years (211 out of 1,245 cues $=16.9 \%$ ) than in his earlier career at RKO ( 31 out of 429 cues $=7.2 \%$ ).

\section{Actions Most Often Mickey-moused}

157 distinct action tags in the database were associated with a "mickey-mousing" tag. The actions most often mickey-moused were "running" (44 times), "falling" (26 times), and "walking" (25 times). 16.2\% of all mickey-mousing cues involved running, and $66.7 \%$ of all cues tagged "running" were mickey-moused.

\section{Film Genres}

All of the films currently in the database are in the crime genre, which makes it difficult to answer this question satisfactorily. However, the data does show that two of the films with a strong comedic element have the highest ratio of cues tagged "mickey-mousing": Crime School (36.7\%) and Angels with Dirty Faces (32.6\%). By contrast, two of the most serious and dark films in the database have the lowest ratio of cues tagged "mickeymousing": The Letter (2\%) and The Unfaithful (3.1\%).

These results are likely to change as more films from a wider variety of genres are added to the database.

\section{Discussion}

In order to more thoroughly evaluate our tagging process, we now consider some numerical data regarding the work that has been completed so far. Of the 32 films that have been fully tagged (about $10 \%$ of Steiner's film scores overall), there have been 15,983 total tags assigned. Here it is worth noting that the earlier RKO films (1930-1936) are generally more sparsely scored (with 4,057 total tags) than the later, more lavish scores for Warner Bros. (11,926 tags). [5] The average number of tags per film is 500 , with a much lower average number of tags for RKO films (194) than for Warner Bros. films (543). Of the films remaining to be tagged, about $60 \%$ will be of the more lavish type, which means that our tagging progress will slow a bit.

Table 3 outlines the distribution of the tags overall. The top 10 tags (such as "leading man," "main theme," and "advance plot") account for $22 \%$ of tags overall. It is possible that some of these tags may be too general or too liberally used, so we might consider replacing them with more specific tags. On the other end of the spectrum, 392 tags were used only once ( $2 \%$ of tags overall). Some of these are specific objects ("shark," "see-saw") or character types ("violinist," "milkman") that we may encounter in later films. Other tags might be too specific (e.g., "punching" = 1 usage while "fighting" = 31) and may need to be generalized in a second pass.

\section{Table 3: Tag distribution}

\begin{tabular}{|l|l|}
\hline Most common tags & \% of all tags \\
\hline Top 10 tags & $22 \%$ \\
\hline Top 20 tags & $34 \%$ \\
\hline Top 50 tags & $50 \%$ \\
\hline Top 100 tags & $63 \%$ \\
\hline Top 200 tags & $77 \%$ \\
\hline Least common tags & $18 \%$ \\
\hline Bottom 996 tags (used 10 times or less) & $18 \%$ \\
\hline Bottom 392 tags (used only once) & $2 \%$ \\
\hline
\end{tabular}

Table 4 further breaks down the distribution of tags by category. The data shows that the five core MACSS categories tend to be more heavily tagged than the others (representing $72 \%$ of all tags assigned). The "film" category is the least heavily tagged (with only $2.3 \%$ ), which might suggest that we need to focus more on this category of tags.[6] The uniformity of scene tags (only $1.5 \%$ unique) is deliberate, since we want to have a limited number of scene types. The abundance of unique "thing" tags is also not surprising, since the objects onscreen tend to be more variable than anything else. 
Table 4: Tag distribution by category

\begin{tabular}{|l|l|l|l|l|}
\hline Category & $\begin{array}{l}\text { Total } \\
\text { tags }\end{array}$ & $\begin{array}{l}\text { \% of all } \\
\text { tags }\end{array}$ & $\begin{array}{l}\text { Tags used } \\
\text { once }\end{array}$ & $\begin{array}{l}\text { \% of tags } \\
\text { used once }\end{array}$ \\
\hline Mood & 2303 & $14.4 \%$ & 35 & $8.9 \%$ \\
\hline Action & 2298 & $14.4 \%$ & 109 & $27.8 \%$ \\
\hline Character & 3553 & $22.2 \%$ & 25 & $6.4 \%$ \\
\hline Setting & 1670 & $10.4 \%$ & 12 & $3.1 \%$ \\
\hline Scene & 1673 & $10.5 \%$ & 6 & $1.5 \%$ \\
\hline Music & 2208 & $13.8 \%$ & 41 & $10.5 \%$ \\
\hline Thing & 1220 & $7.6 \%$ & 138 & $35.2 \%$ \\
\hline Analytical & 689 & $4.3 \%$ & 19 & $4.8 \%$ \\
\hline Film & 369 & $2.3 \%$ & 7 & $1.8 \%$ \\
\hline
\end{tabular}

OpenRefine has helped us to identify additional issues in our current tagging process. Using the "Cluster \& Edit" tool,[7] we found 37 clusters of inconsistently formatted tags, seven of which needed attention. These clusters are made up of tags that should be narrowed down to a single tag, resolving issues such as verb tense, plurality, spelling, and hyphen usage. One example of such a cluster is "photograph/photographs/photography." The cluster tool also found 98 clusters of tags appearing in multiple categories, 46 of which needed attention. Although the same tag in different categories sometimes has a different meaning (such as the tag "Chinese" in the music category vs. the character category), other tags were indeed categorized incorrectly. These inconsistencies are largely found in the earlier films that we tagged, indicating how our procedures have improved over time.

\section{Conclusion}

Consistent tagging of metadata is crucial to finding results in a corpus. We will continue to refine our tagging process as our analysis of Steiner's corpus progresses. We expect that as data from films in other genres (beyond crime) is added to the database, new sets of tags will need to be created in each of the categories. For example, Westerns will have different settings than films noir. Romances will have different characters than thrillers. As the tagging data in the Max Steiner Digital Thematic Catalog grows, film scholars will be able to answer many more questions about practices in Classic Hollywood film scoring.

\section{Acknowledgements}

We would like to acknowledge the Film Music Archives in the L. Tom Perry Special Collections department of the Harold B. Lee Library at Brigham Young University for their role in preserving and providing access to the materials in the Max Steiner Collection.

\section{End Notes}

[1] Currently, our corpus includes 315 films by Steiner, with an additional 34 films categorized as lost, hard to find, or difficult to determine actual authorship based on current information.

[2] Combined with the core categories of MACSS, these optional categories form the acronym MMMAACTTSS (both being a tribute to Max).

[3] For example, we have decided that mood tags should be adjectives (anxious, playful, sentimental), action tags should be gerunds (jumping, spinning, climbing), and character tags should be nouns (guard, sheriff, victim).

[4] The Unique Tags and Tag Data tools also help us to identify underused and newly-established tags that we will want to consider in future tagging sessions.

[5] If we omit one notable outlier, Steiner's 1935 Oscarwinning score for The Informer, the average number of music cues for each RKO film is only 14 , as compared to an average of 104 cues for Warner Bros. films.

[6] Although the "analytical" category also appears to be low in this table $(4.3 \%)$, the tagging process for this category actually lags behind the others due to the time needed to complete the separate step of score analysis (from the transcriptions).

[7] We used the "nearest neighbor - Levenshtein" function using a radius of 1.0 and 6 block characters.

\section{References}

Lyon, J. \& Yorgason, B. (2021). Cataloguing Max Steiner: A Corpus Study of Film Scores. Journal of Film Music, 9(1-2).

Yorgason, B. \& Lyon, J. (2020). Fanfare as Fulcrum: A Pivotal Event in Max Steiner's Theme for Warner Brothers. Music Theory Online, 26(2). https://doi.org/10.30535/mto.26.2.12

(2021). Fanning out from the Fanfare: Max Steiner's Theme for Warner Brothers. Journal of Film Music, 9(1-2). 